\title{
Effect of Slurry Composting Biofiltration (SCB) Liquid Manure on Shoot Growth and Fruit Qualities of Peach (Prunus persica L.) and Soil Chemical Properties in Orchard
}

\author{
Jin Myeon Park*, Seong Eun Lee, Tae Jun Lim, and Jae Seung Noh \\ Horticultural \& Herbal Crop Environment Division, Narional Insititute of Horticultural \& Herbal Science, \\ Suwon 441-440, Korea
}

(Received: September 24 2013, Accepted: November 24 2013)

This study was carried out to investigate the effect of slury composting and biofiltration (SCB) liquid manure application on shoot growth, fruit qualities and soil chemical properties in peach orchard. SCB liquid manure was fertigated ten times from April to October in SCB plot, whereas chemical fertilizer was treated two times as basal and additional fertilizers in control plot. The shoot growth, leaf nitrogen and potassium content, soil exchangeable K, fruit weight and yield were higher in SCB plot than in control. Soluble solid content and acidity, soil organic matter, soil available phosphate and soil exchangeable Mg showed no significant difference between treatments, and the leaf calcium and magnesium content were lower in SCB plot than in control. In conclusion, fertigating SCB liquid manure in peach orchard has positive effects on fruit weight and yield, and it is suggested that periodical soil testing is needed because of the possibility of $\mathrm{K}$ accumulation in SCB liquid manure treated soil when the orchard is fertigated based on the soil nitrogen content.

Key words: Liquid manure, Shoot growth, Fruit quality, Soil, Peach

Effect of chemical fertilizer and SCB liquefied fertilizer on the fruit weight of peach.

\begin{tabular}{lcc}
\hline \hline Treatment & 2012 & 2013 \\
\hline & $--12-0-13$ & $336.6 \sim 391.5$ \\
SCBLF $\dagger$ & $336.4 \sim 468.4$ & $315.5 \sim 318.8$ \\
\hline
\end{tabular}

†SCBLF: slurry composting biofiltration liquefied fertilizer. 


\section{Introduction}

우리나라에서 발생되는 가축분뇨의 발생량은 2012년 기 준 4,649만톤이며 이 중에서 $88.7 \%$ 인 4,124 만톤이 퇴비나 액비로 자원화 되고 있다 (MAFRA, 2013). 이 중 양돈 분뇨 는 1,775 만톤으로 전체 가축분뇨 발생량의 $38.2 \%$ 를 차지하 고 있으나 수분이 많은 형태로 취급이 곤란하고 원거리 수 송시 비용이 발생하기 때문에 발생지 주변에서 처리하는 것 이 경제적이다. 가축분뇨의 비료로서 자원화는 양돈농가의 어려움을 해결함과 동시에 경종농가에 대한 유기 비료를 공 급할 수 있어 자원 순환 시스템으로 활용 가능하다. 가축분 뇨 액비는 상당 부분이 벼농사에 사용되고 있으나 대부분 모내기 전에만 사용되는 등 특정 시기에 사용이 집중되고 있어 연중 분산 이용될 수 있도록 여러 작물에 대한 이용 확 대가 요구되고 있다. 가축분뇨 액비의 농업적 이용은 농축 산 유기자원의 재활용, 영농비 경감, 각종 양분의 공급, 중 소 동물 및 미생물의 다양성 증대, 물질의 순환 개념 등 여 러 가지 이점이 있다. 따라서 악취 발생, 양분함량의 불균 형, 취급 어려움 등 몇 가지 약점만 해결된다면 과수원에서 액비 활용은 비료 대체 공급에 의한 경영비 절감과 자원 순 환농업을 위해서 적극적으로 검토할 필요가 있다. 양돈분뇨 의 액비화는 그동안 외국에서도 많은 연구가 진행되어 왔다 (Ceotto와 Spallacci, 2006; Tani et al., 2006).

가축분뇨의 액비화 기술은 제조 방법에 따라 호기성 액비화, 혐기성 액비화 및 퇴비단 여과액비 (SCB; Slurry Composting \& Biofiltration) 방법으로 나눈다 (RDA, 1999). 가축분 액 비의 원예작물에 대한 시용 연구는 2000 년 이후에 이루어 졌다. 배 과수원에서 돈분슬러리 액비에 대한 생육반응은 액비 처리구가 화학비료보다 많은 경향을 보였고 수량은 질 소 $75 \%$ 에 해당하는 액비 시용구와 화학비료 시용구가 같았 다 (Won et al., 2002). Ro et al. (2008a)은 돈분액비 원액 과 퇴비단 여과 저농도 액비의 질소변환에 미치는 수분 영 향을 연구하였으며 돈분액비 시용량이 증가함에 따라 질소 와 인이 용탈수와 유거수에서 함량이 높다고 하였다 (Ro et al., 2008b). SCB 액비는 정식 전 기비로 고추 (Lim et al., 2008)와 배추 (Lim et al., 2009)를 재배하거나 시설토마토 (Park et al., 2010)와 시설오이 (Park et al., 2011) 재배에 서 관비를 했을 때 화학비료와 대등한 효과가 있었으며 시 설하우스 조건에서 5년간 오이와 토마토 (Seo et al., 2011) 를 재배했을 때 화학비료와 수량은 같았으며 중금속의 축적 우려는 없었다. 배 과원에서 $\mathrm{SCB}$ 액비를 질소와 칼리함량 기준으로 기비와 추비 형태로 이용했을 때 화학비료와 대등 한 효과가 있었다 (Park et al., 2012).

본 연구는 $\mathrm{SCB}$ 액비가 비교적 균질하고 부유물이 적어 관비가 가능할 것으로 판단되어 복숭아 과수원에 $\mathrm{SCB}$ 액비 를 3년 동안 관비처리했을 때 복숭아나무의 신초 생장과 잎 의 무기성분 함량, 과실특성 및 토양 양분함량의 변화를 조 사하여 관비로 시용할 때 화학비료 대체 가능성을 검토하고 자 수행하였다.

\section{Materials and methods}

처리내용 및 방법 복숭아 과원에 대한 $\mathrm{SCB}$ 액비 시험 은 2011년부터 2013년까지 3년간 수원시 이목동연구소와 세종시 연서면 농가 2곳에서 천중도 백도 품종 8 년생과 10 년생을 이용하였으며 재식거리는 $6 \times 5 \mathrm{~m}$ 이었다. 시험 처리 는 화학비료와 $\mathrm{SCB}$ 액비 관비 시용 2 처리로 3 반복이며 반 복당 5 주를 이용하였다. 토양 검정에 의한 복숭아 시비처방 기준 (RDA, 2010)에 의하여 화학비료 시비량은 질소 $90 \mathrm{~kg}$ $\mathrm{ha}^{-1}$, 인산 40 $50 \mathrm{~kg} \mathrm{ha}$, 칼리 $55 \mathrm{~kg} \mathrm{ha}{ }^{-1}$ 이며 SCB 액비 처리량은 질소 시비량 기준으로 액비 중 질소 함량을 고려 하여 액비 시용량을 결정하였다. 처리 방법 중 화학비료 중 질소와 칼리는 기비와 추비로 나누어 시용 비율은 질소는 $5: 5$, 칼리는 $8: 2$ 로 2 회 분시하였으며 인산은 $100 \%$ 기비로 시용하였다. SCB 액비는 장마기를 제외한 4월 중순부터 6 월 중순까지 15 일 간격으로 5 회, 7 월 하순부터 9 월 하순까 지 15 일 간격으로 5 회, 총 10 회를 관비하였으며 1 회 관비량 은 1 $2 \mathrm{~mm}$ 처리되었다. 토양수분함량은 $-30 \mathrm{kPa}$ 을 관수

Table 1. Soil chemical properties of peach orchard used in this experiment.

\begin{tabular}{|c|c|c|c|c|c|c|}
\hline \multirow{2}{*}{ Location } & \multirow{2}{*}{$\mathrm{pH}$} & \multirow{2}{*}{ O.M } & \multirow{2}{*}{ Avail. $\mathrm{P}_{2} \mathrm{O}_{5}$} & \multicolumn{3}{|c|}{ Exch. Cation } \\
\hline & & & & $\mathrm{K}$ & $\mathrm{Ca}$ & $\mathrm{Mg}$ \\
\hline & $1: 5$ & $\mathrm{~g} \mathrm{~kg}^{-1}$ & $\mathrm{mg} \mathrm{kg}^{-1}$ & \multicolumn{3}{|c|}{ 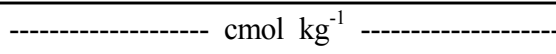 } \\
\hline Suwon & 7.5 & 18.2 & 567 & 0.94 & 4.32 & 2.68 \\
\hline Sejong & 6.6 & 15.5 & 212 & 0.72 & 3.34 & 1.86 \\
\hline
\end{tabular}

Table 2. Mineral content of slury composting biofiltration liquid fertilizer (SCB) used in this experiment.

\begin{tabular}{|c|c|c|c|c|}
\hline $\mathrm{T}-\mathrm{N}$ & $\mathrm{NO}_{3}-\mathrm{N}$ & $\mathrm{NH}_{4}-\mathrm{N}$ & $\mathrm{P}_{2} \mathrm{O}_{5}$ & $\mathrm{~K}_{2} \mathrm{O}$ \\
\hline $697 \pm 212.7$ & $26 \pm 19.8$ & $506 \pm 161.4$ & $59 \pm 24.7$ & $2,367 \pm 1,715.9$ \\
\hline
\end{tabular}


개시점으로 관리하였다. 시험에 사용된 $\mathrm{SCB}$ 액비의 화학성 은 Table 1과 같이 전질소함량 $697 \mathrm{mg} \mathrm{kg}^{-1}$, 인산함량 59 $\mathrm{mg} \mathrm{kg}$, 칼리함량 $2,367 \mathrm{mg} \mathrm{kg}^{-1}$ 으로 칼리성분에 비하여 질소와 인산성분이 낮았으며 일반적인 $\mathrm{SCB}$ 액비 $(\mathrm{RDA}$, 2012)보다 질소, 인산 및 칼리함량이 약간 낮았다. 액비 성 분의 표준편차가 큰 것은 3 년간 평균으로 연도에 따라 액비 의 농도 차이로 나타난 결과이다.

시험 전 토양의 화학성 중 수원은 $\mathrm{pH}$ 가 7.5로 약간 높았 고 유기물함량은 낮으나 인산함량은 $567 \mathrm{mg} \mathrm{kg}^{-1}$ 으로 높았 다. 세종은 유기물과 치환성 칼슘만 조금 낮은 상태이었다 (Table 2).

조사 및 분석방법 시험 처리 전·후 토양 화학성과 잎 분석을 위한 복숭아나무 잎 시료 채취는 생육 중기인 7월 하순에 채취하였다. 토양 시료는 Soil auger를 이용하여 주 간으로부터 중간부위의 표층 $5 \sim 15 \mathrm{~cm}$ 깊이의 훍을 채취하 여 음건 후 $2 \mathrm{~mm}$ 체로 걸러 분석하였다. 잎 시료는 신초 중 간의 완전 전개된 잎을 신초당 $2 \sim 3$ 매, 반복당 50 매 정도를 채취하여 세척한 후 $70^{\circ} \mathrm{C}$ 에서 건조하여 잎의 무기성분 분 석에 이용하였다. 신초 생육은 과실 수확이 끝난 후 처리당 3 주를 선정하여 주당 25 개 신초를 측정한 후 평균값을 이용 하였으며 과실 특성과 수량은 수확기에 채취하여 조사하였 다. 과중은 1 반복당 20 개씩 3 반복으로 조사하였다.

토양 및 식물체 분석은 토양화학분석법 (NIAST, 2000)의 토양 및 식물체 분석법에 준하였다. 토양 $\mathrm{pH}$ 는 토양과 물의 비율을 $1: 5$ 로 하여 초자전극법으로 측정하였고, 토양 유기 물은 Tyurin 법, 유효인산은 Lancaster 법, 교환성 $\mathrm{K}, \mathrm{Ca}$, $\mathrm{Mg}$ 은 $1 \mathrm{~N} \mathrm{CH}_{3} \mathrm{OOONH}$ ( $\mathrm{pH}$ 7.0) 완충용액으로 침출하여 ICP-OES (SDS-720, GBC, Australia)를 사용하여 측정하였다. 액비 성분 중 암모니아태 질소는 액비 $20 \mathrm{ml}$ 에 $\mathrm{MgO}$ 분말을 가하 고 켈달장치 (Kjeltec 8400, Foss, Sweden)로 증류한 후 적 정하였으며 질산태 질소는 Devarda alloy를 가하여 질산태 질소를 암모니아태 질소로 전환시켜 증류한 후 $0.01 \mathrm{~N}$ 황산 표준용액으로 적정하여 계산하였다. 식물체 무기성분 중 질 소 측정은 식물체 시료 $0.5 \mathrm{~g}$ 을 황산염 혼합분말 $\left(\mathrm{K}_{2} \mathrm{SO}_{4}\right.$ 와 $\mathrm{CuSO}_{4}=9: 1$ )과 농황산을 넣고 분해한 후 켈달장치 (Kjeltec
8400, Foss, Sweden)를 이용하여 증류한 후 적정하였다. 인은 ammonium vanadate 법으로 비색계 (UV/VIS spectrophotometer, Cintra $6 \mathrm{GBC}$, Australia)를 사용하여 정량하였고, 칼륨과 칼슘 및 마그네슘은 ICP-OES (MX2, GBC, Australia)로 측 정하였다. 과실 특성 중 가용성 고형분 함량은 굴절당도계 (ATAGO, Brix 0-32\%)로 측정하였고, 산도는 과육을 착즙 하여 $0.1 \mathrm{~N} \mathrm{NaOH}$ 로 적정한 후 malic acid로 환산하여 백분 율로 나타내었다. 통계분석은 SAS 통계프로그램 (v. 9.2)을 이용하였다.

\section{Results and Discussion}

신초 생장 비교 화학비료와 $\mathrm{SCB}$ 액비를 관비했을 때 복숭아나무의 신초 생장에 미치는 영향은 Table 3 과 같다. 수원에서는 $\mathrm{SCB}$ 액비 처리가 화학비료 처리보다 신초 생장 이 많았으나 세종에서는 처리간에 유의성이 없었다. Kwon et al. (2009)과 Lee et al. (2011)은 밤나무에 대한 시험에서 $\mathrm{SCB}$ 액비 처리했을 때 화학비료와 대등하거나 좋은 경우가 있다고 하여 본 연구와 일치하였다.

잎의 무기성분 함량 비교 화학비료와 $\mathrm{SCB}$ 액비를 관 비했을 때 (Table 4) 복숭아나무 잎의 무기성분 함량 중 질 소와 칼리는 2012년과 2013년에 SCB 액비 처리구가 높았으 나 칼슘과 마그네슘 함량은 2012년에 SCB 액비 처리에서 낮았다. $\mathrm{SCB}$ 액비 처리구에서 질소함량이 높은 것은 관비 를 실시하여 흡수 효율이 높아 나타난 것이며 칼리함량이 높은 것은 화학비료 시용량보다 $\mathrm{SCB}$ 액비 처리에서 칼리 시비 기준량보다 해에 따라 $15.2 \sim 353.2 \mathrm{~kg} \mathrm{~h}^{-1}$ 칼리가 많 이 처리되었기 때문으로 판단되었다. $\mathrm{SCB}$ 액비 처리구에서 칼슘과 마그네슘 함량이 낮았던 것은 $\mathrm{SCB}$ 액비 처리구에서 칼리 흡수량이 많아 길항작용으로 칼슘과 마그네슘의 흡수 가 억제되어 나타난 것으로 판단되었다. Park et al. (2012) 은 배 과원에서 $\mathrm{SCB}$ 액비를 시용했을 때 화학비료 처리보 다 칼리 시용량이 106 $557 \mathrm{~kg} \mathrm{ha}^{-1}$ 많이 처리되어도 배나 무 잎의 칼리함량이 증가하지 않았다고 보고하여 본 연구와 다른 경향을 보였는데, 이는 배나무가 복숭아나무보다 비료

Table 3. Effect of chemical fertilizer and SCB liquefied fertilizer on shoot growth of peach tree in 2013.

\begin{tabular}{|c|c|c|}
\hline \multirow{2}{*}{ Treatment } & \multicolumn{2}{|c|}{ Shoot length } \\
\hline & Suwon & Sejong \\
\hline & \multicolumn{2}{|c|}{------------------------------ cm ----------------------------- } \\
\hline $\mathrm{SCBLF} \dagger$ & 63.7 & 83.8 \\
\hline Chemical ferti. & 60.6 & 82.1 \\
\hline t-test & $* \ddagger$ & NS \\
\hline
\end{tabular}

†SCBLF: slurry composting biofiltration liquefied fertilizer.

$\ddagger \mathrm{NS}$, * Nonsignificant or significant at $P=0.05$, respectively. 
Table 4. Effect of chemical fertilizer and SCB liquefied fertilizer on the mineral content of leaf in peach.

\begin{tabular}{|c|c|c|c|c|c|c|c|}
\hline Years & Location & Treatments & $\mathrm{N}$ & $\mathrm{P}$ & $\mathrm{K}$ & $\mathrm{Ca}$ & $\mathrm{Mg}$ \\
\hline \multirow{5}{*}{2011} & & & ----- & 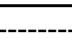 & $\mathrm{g} \mathrm{kg}^{-1}$ & - & 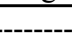 \\
\hline & \multirow{2}{*}{ Suwon } & SCBLF $\dagger$ & 33.0 & 2.53 & 28.7 & 16.4 & 4.70 \\
\hline & & Chemical ferti. & 32.5 & 2.69 & 26.7 & 15.4 & 4.71 \\
\hline & \multirow{2}{*}{ Sejong } & SCBLF & 34.2 & 2.05 & 28.3 & 12.5 & 3.70 \\
\hline & & Chemical ferti. & 33.1 & 1.98 & 28.3 & 14.0 & 4.01 \\
\hline \multirow{4}{*}{2012} & \multirow{2}{*}{ Suwon } & SCBLF & 30.6 & 1.96 & 24.0 & 15.8 & 4.40 \\
\hline & & Chemical ferti. & 27.0 & 2.31 & 22.2 & 20.8 & 5.88 \\
\hline & \multirow{2}{*}{ Sejong } & SCBLF & 33.0 & 1.80 & 29.7 & 20.4 & 5.69 \\
\hline & & Chemical ferti. & 33.5 & 2.03 & 28.9 & 21.0 & 5.71 \\
\hline \multirow{4}{*}{2013} & \multirow{2}{*}{ Suwon } & SCBLF & 32.4 & 1.74 & 31.4 & 21.0 & 5.04 \\
\hline & & Chemical ferti. & 32.3 & 1.91 & 27.7 & 20.5 & 4.89 \\
\hline & \multirow{2}{*}{ Sejong } & SCBLF & 34.1 & 2.20 & 31.3 & 19.1 & 4.61 \\
\hline & & Chemical ferti. & 32.3 & 2.44 & 28.3 & 20.2 & 4.96 \\
\hline \multirow{6}{*}{ t-test } & \multirow{2}{*}{2011} & Suwon & NS $\ddagger$ & NS & NS & NS & NS \\
\hline & & Sejong & NS & NS & NS & NS & NS \\
\hline & \multirow{2}{*}{2012} & Suwon & $* *$ & NS & $*$ & $* *$ & $*$ \\
\hline & & Sejong & NS & $*$ & NS & NS & NS \\
\hline & \multirow{2}{*}{2013} & Suwon & NS & NS & $*$ & NS & NS \\
\hline & & Sejong & $*$ & NS & $*$ & NS & NS \\
\hline
\end{tabular}

†SCBLF: slurry composting biofiltration liquefied fertilizer.

$\ddagger \mathrm{NS}, * * *$ Nonsignificant or significant at $P=0.05$ or 0.01 , respectively.

Table 5. Effect of chemical fertilizer and SCB liquefied fertilizer on the yield and fruit qualities of peach.

\begin{tabular}{|c|c|c|c|c|c|c|}
\hline Year & Location & Treatment & Yield & Fruit weight & Soluble solids & Acidity \\
\hline \multirow{5}{*}{2011} & \multirow{3}{*}{ Suwon } & & $\mathrm{Mg} \mathrm{ha}^{-1}$ & $\mathrm{~g} \mathrm{ea}^{-1}$ & ${ }^{\circ} \mathrm{Bx}$ & $\%$ \\
\hline & & $\mathrm{SCBLF}^{\dagger}$ & - & 235.1 & 10.0 & 0.31 \\
\hline & & Chemical ferti. & - & 231.2 & 9.6 & 0.30 \\
\hline & \multirow{2}{*}{ Sejong } & SCBLF & - & 336.2 & 10.8 & 0.21 \\
\hline & & Chemical ferti. & - & 335.0 & 10.9 & 0.25 \\
\hline \multirow{4}{*}{2012} & \multirow{2}{*}{ Suwon } & SCBLF & 12.7 & 336.4 & 12.9 & 0.24 \\
\hline & & Chemical ferti. & 11.3 & 288.3 & 11.8 & 0.25 \\
\hline & \multirow{2}{*}{ Sejong } & SCBLF & 16.2 & 468.4 & 13.5 & 0.27 \\
\hline & & Chemical ferti. & 15.8 & 419.8 & 12.8 & 0.29 \\
\hline \multirow{4}{*}{2013} & \multirow{2}{*}{ Suwon } & SCBLF & 12.0 & 336.6 & 12.8 & 0.24 \\
\hline & & Chemical ferti. & 11.1 & 315.5 & 12.7 & 0.25 \\
\hline & \multirow{2}{*}{ Sejong } & SCBLF & 15.6 & 391.5 & 11.5 & 0.23 \\
\hline & & Chemical ferti. & 13.3 & 318.8 & 11.1 & 0.23 \\
\hline \multirow{6}{*}{ t-test } & \multirow{2}{*}{2011} & Suwon & - & NS $\ddagger$ & NS & NS \\
\hline & & Sejong & - & NS & NS & NS \\
\hline & \multirow{2}{*}{2012} & Suwon & NS & $* *$ & $*$ & NS \\
\hline & & Sejong & NS & $* *$ & NS & NS \\
\hline & \multirow{2}{*}{2013} & Suwon & $*$ & NS & NS & NS \\
\hline & & Sejong & $*$ & $* *$ & NS & NS \\
\hline
\end{tabular}

$\uparrow$ SCBLF: slurry composting biofiltration liquefied fertilizer.

$\ddagger$ NS, *, ** Nonsignificant or significant at $P=0.05$ or 0.01 , respectively.

반응이 둔감하여 나타난 것으로 추정되었다. Kang et al. (2011a)은 옥수수 재배시 SCB 액비 시용 후 강우량에 비례 하여 칼리함량이 낮아지나 치환성 칼리함량이 높게 유지되 어 상당량이 집적된다고 하였다.
과실 수량과 특성 비교 $\mathrm{SCB}$ 액비 관비와 화학비료를 표층시비 했을 때 복숭아 수량 및 과실 특성은 Table 5 와 같 다. 수량 조사는 2011년에 이루어지지 않았으며 2012년에는 처리간에 차이가 없었으나 2013년에는 SCB 액비 처리구가 
534 Effect of Slurry Composting Biofiltration (SCB) Liquid Manure on Shoot Growth and Fruit Qualities of Peach (Prunus persica L.) and Soil Chemical Properties in Orchard

Table 6. Effect of chemical fertilizer and SCB liquefied fertilizer on the soil chemical properties in peach orchard.

\begin{tabular}{|c|c|c|c|c|c|c|c|c|}
\hline \multirow{2}{*}{ Year } & \multirow{2}{*}{ Location } & \multirow{2}{*}{ Treatment } & \multirow{2}{*}{$\mathrm{pH}$} & \multirow{2}{*}{ O.M. } & \multirow{2}{*}{ Avail. $\mathrm{P}_{2} \mathrm{O}_{5}$} & \multicolumn{3}{|c|}{ Exch. Cation } \\
\hline & & & & & & K & $\mathrm{Ca}$ & $\mathrm{Mg}$ \\
\hline & & & $1: 5$ & $\mathrm{~g} \mathrm{~kg}^{-1}$ & $\mathrm{mg} \mathrm{kg}^{-1}$ & - & $\mathrm{mol} \mathrm{kq}$ & - \\
\hline \multirow{4}{*}{2011} & \multirow{2}{*}{ Suwon } & SCBLF† & 7.6 & 17.1 & 466.3 & 0.97 & 5.68 & 2.32 \\
\hline & & Chemical ferti. & 7.0 & 16.2 & 445.4 & 0.80 & 4.70 & 2.15 \\
\hline & \multirow{2}{*}{ Sejong } & SCBLF & 5.9 & 14.6 & 144.4 & 0.72 & 3.08 & 2.04 \\
\hline & & Chemical ferti. & 5.7 & 15.9 & 108.1 & 0.61 & 2.98 & 1.60 \\
\hline \multirow{4}{*}{2012} & \multirow{2}{*}{ Suwon } & SCBLF & 7.5 & 18.9 & 435.9 & 2.03 & 4.46 & 1.80 \\
\hline & & Chemical ferti. & 6.9 & 18.0 & 412.4 & 1.28 & 4.27 & 1.87 \\
\hline & \multirow{2}{*}{ Sejong } & SCBLF & 6.8 & 17.8 & 188.7 & 1.19 & 4.07 & 2.00 \\
\hline & & Chemical ferti. & 6.2 & 15.8 & 166.1 & 1.09 & 3.45 & 1.65 \\
\hline \multirow{4}{*}{2013} & \multirow{2}{*}{ Suwon } & SCBLF & 7.2 & 14.5 & 499.3 & 1.69 & 4.62 & 2.15 \\
\hline & & Chemical ferti. & 6.7 & 16.5 & 496.4 & 1.49 & 4.58 & 2.17 \\
\hline & \multirow{2}{*}{ Sejong } & SCBLF & 6.6 & 15.7 & 244.3 & 1.26 & 4.55 & 2.10 \\
\hline & & Chemical ferti. & 6.6 & 16.3 & 256.3 & 1.03 & 4.97 & 1.81 \\
\hline \multirow{6}{*}{ t-test } & \multirow{2}{*}{2011} & Suwon & $\mathrm{NS} \ddagger$ & NS & NS & NS & $*$ & NS \\
\hline & & Sejong & NS & NS & NS & NS & NS & NS \\
\hline & \multirow{2}{*}{2012} & Suwon & $* *$ & NS & NS & $*$ & NS & NS \\
\hline & & Sejong & NS & NS & NS & NS & NS & NS \\
\hline & \multirow{2}{*}{2013} & Suwon & NS & NS & NS & NS & NS & NS \\
\hline & & Sejong & NS & NS & NS & NS & NS & NS \\
\hline
\end{tabular}

†SCBLF: slurry composting biofiltration liquefied fertilizer.

$\ddagger \mathrm{NS}, * * *$ Nonsignificant or significant at $P=0.05$ or 0.01 , respectively.

많았다. 과중은 2011년에는 처리간에 차이가 없었으나 2012 년과 2013년에는 SCB 액비 처리구가 컸다. 당도와 산도는 처리간에 차이가 없었다. Lee et al. (2011)은 저농도 액비처 리에 따른 밤나무 과실 품질에서 액비 처리구가 대과 비율 이 가장 높았다고 하여 복숭아나무에서 액비 시용 결과와 일치하였다. Park et al. (2012)은 배나무에서 SCB 액비와 화 학비료 처리를 비교했을 때 수량과 과중이 증가하는 경향이 나 통계적인 유의성은 없다고 하여 복숭아나무보다 배나무 가 비료 반응이 둔감한 것으로 판단되었다.

토양 화학성 비교 복숭아 과원에서 $\mathrm{SCB}$ 액비 시용에 따른 토양 화학성 변화는 Table 6과 같다. $\mathrm{pH}$ 는 $\mathrm{SCB}$ 액비 처리구가 높은 경향이나 유의성은 없었으나 2012년 수원의 $\mathrm{SCB}$ 액비 처리구에서 $\mathrm{pH}$ 가 높았다. 이는 액비가 알칼리성 으로 영향을 미친 것으로 Park et al. (2012) 보고와 일치하 였다. 유기물함량, 유효인산 함량과 치환성 마그네슘 함량 은 처리간에 차이가 없고 치환성 칼리함량은 $\mathrm{SCB}$ 액비 처 리가 높은 경향이나 통계적인 유의성은 없었고 2012년 수원 의 SCB 액비 처리에서 칼리함량이 많았다. Kang et al. (2011b)은 제주지역에서 돈분 액비를 사용하여 감자를 재배 했을 때 화학비료 처리가 돈분액비 처리에 비하여 $\mathrm{pH}$ 가 낮 았고 치환성 칼륨함량은 화학비료 처리보다 돈분액비 처리
구에서 높다고 하였다. 본 연구에서도 질소 시비 기준으로 $\mathrm{SCB}$ 액비를 처리함에 따라 칼리 기준량보다 $106 \sim 557 \mathrm{~kg}$ $\mathrm{ha}^{-1}$ 많이 처리되어 화학비료 처리보다 높게 유지되고 있어 Kang et al. (2011a)과 Park et al. (2012) 보고와 일치하였 다. Won et al. (2002)에 의하면 돈분 액비 시용량을 질소 기준으로 $200 \%, 300 \%, 400 \%$ 으로 증가하면 토양 중에 인산 과 칼리함량은 증가하였으나 $\mathrm{pH}$, 유기물 칼슘과 마그네슘 함량은 차이가 없다고 하여 본 연구와 같은 경향을 보이고 있다.

\section{Conclusion}

$\mathrm{SCB}$ 액비를 관비 형태로 분산하여 시용했을 때 복숭아 생 육에 긍정적으로 작용하여 과중과 수량이 증가하였고 토양 중에는 치환성 칼리함량이 증가하여 축적되는 경향을 보였 으나 문제가 될 정도는 아니었다. $\mathrm{SCB}$ 액비는 질소 대비 인 산함량이 매우 낮기 때문에 질소 기준으로 시용량을 결정하 여도 인산이 축적될 우려는 적으나 질소 대비 칼리함량이 높기 때문에 질소 기준량으로 시용량을 결정하면 칼리가 축 적될 우려가 있으므로 주기적인 토양 검정을 통하여 칼리가 축적되지 않도록 주의할 필요가 있다고 판단되었다. 


\section{References}

Ceotto, E. and P. Spallacci. 2006. Pig slurry applications to alfalfa: Productivity, solar radiation utilization, $\mathrm{N}$ and $\mathrm{P}$ removal. Field Crops Research. 95:135-155.

Kang, S.S, M.K. Kim, S.I. Kwon, M.S. Kim, S.W. Yoon, S.G. Ha, and Y.H. Kim. 2011a. The effect of application levels of slurry composting and biofiltration liquid fertilizer on soil chemical properties and growth of radish and corn. Korean J. Soil Sci. Fert. 44(6):1306-1313.

Kang, H.J., S.H. Yang, and S.C. Lee. 2011b. Effects of liquid pig manure on growth of potato, soil chemical properties and infiltration water quality. Korean J. Soil Sci. Fert. 44(6): 1130-1136.

Kwon, Y.H., U. Lee, S.I. Hwang, and E.S. Baik. 2009. The characteristics of growth and fruiting in chestnut trees by SCB (Slurry composting and biofiltration) liquid fertilizer. Jour. Korean For. Soc. 98(6):676-680.

Lee, U, S.I. Hwang, M.J. Kim, and J.H. Kim. 2011. Growth and fruiting characteristics, and nut qualities of Castanea crenata by low-concentrated liquid fertilizer. Jour. Korean For. Soc. 100(3):432-440.

Lim, T.J., S.D. Hong, S.H. Kim, and J.M. Park. 2008. Evaluation of yield and quality from red pepper for application rates of pig slurry composting biofilatration. Korean J. Environ. Agric. 27(2):171-177.

Lim, T.J., S.D. Hong, S.B. Kang, and J.M. Park. 2009. Evaluation of preplant optimum application rates of pig slurry composting biofiltration for chinese cabbage. Kor. J. Hort. Sci. Technol. 27:572-577.

Ministry of Agriculture Food and Rural Affairs (MAFRA). 2013. Medium and long term livestock manure recycling counterplan.

NIAST. 2000. Methods of soil chemical analysis. National Institute of Agricultural Science and Technology, Sammikihoek, Suwon, Korea.

Park, J.M., T.J. Lim, S.B. Kang, I.B. Lee, and Y.I. Kang. 2010. Effect of pig slurry fertigation on soil chemical properties and yield of tomato (Lycopersicon esculentum Mill.) Korean J. Soil
Sci. Fert. 43(5):488-493.

Park, J.M., T.J. Lim, S.E. Lee, and I.B. Lee. 2011. Effect of pig slurry fertigation on soil chemical properties and growth and development of cucumber (Cucumis sativus L.). Korean J. Soil Sci. Fert. 44(2):194-199.

Park, J.M., T.J. Lim, and S.E. Lee. 2012. Effect of pig slurry application on the mineral content of leaf, fruit quality and soil chemical properties in pear orchard. Korean J. Soil Sci. Fert. 45(2):209-214.

Ro, H.M., L.S. Kim, M.J. Lee, H.J. Choi, and C.H. Park. 2008a. Soil moisture regime affects variation patterns in concentration of inorganic nitrogen from liquid swine manure during aerobic incubation. Korean J. Soil Sci. Fert. 41(1):34-37.

Ro, H.M., H.J. Choi, S.I. Yun, M.J. Lee, J.M. Kim, H.L. Choi, and K. Zhu. 2008b. Growth of chinese cabbage and losses of non-point sources from runoff and leaching in soils as affected by anaerobically digested liquid pig slurry. Korean J. Soil Sci. Fert. 41:112-117.

Rural Development Adminstration (RDA). 1999. Manufacturing and appling of compost and liquid fertilizer with swine slurry. Munyoungdang. Suwon. Korea.

Rural Development Adminstration (RDA). 2010. Fertilization Standard of Crop Plants. Sangroksa. Suwon, Korea.

Rural Development Adminstration (RDA). 2012. Quality control and appling of compost and liquid fertilizer with swine slurry. Sangroksa. Suwon. Korea.

Seo, Y.H., M.S. Ahn, A.S. Kang, and Y.S. Jung. 2011. Influence of continuous application of low-concentration swine slurry on soil properties and yield of tomato and cucumber in a greenhouse. Korean J. Soil Sci. Fert. 44(5):773-778.

Tani, M., N. Sakamoto., T. Kishimoto, and K. Umetsu. 2006. Utilization of anaerobically digested dairy slurry combined with other wastes following application to agricultural land. International Congress Series. 1293:331-334.

Won, S.N., K.R. Jo, and K.Y. Park. 2002. Effect of livestock liquid fertilizer (pig slurry) appling in pear orchard. pp. 634-645. In Research report of gyeonggi-do agricultural research. Gyeonggi-Do Agricultural Research \& Extension Services. Hwasung, Korea. 